\title{
El papel estratégico de la política de género en educación
}

\section{Eduardo López Herrera}

Sin lugar a dudas, la igualdad de oportunidades de hombres y mujeres en los diferentes ámbitos de la sociedad, sienta las bases para impulsar el desarrollo, sobre todo reconociendo el invaluable papel de la mujer, como un sujeto alrededor del cual giran muchas acciones y en particular, el interés de que sus hijos sean algo en la vida, pero que muchas veces son sueños truncados por las limitantes estructurales que padecen y que están relacionadas con la subordinación histórica ante el sexo opuesto y el peso de siglos de una sociedad patriarcal.

Si bien es cierto que la falta de acceso a la educación de hombres y mujeres en una sociedad, limita el desarrollo individual y social y fortalece el circulo de pobreza, no es menos cierto que la falta de instrucción o formación profesional de las mujeres profundiza ese circulo, a pesar del papel relevante que tienen; pero que lamentablemente esa relevancia no se traduce en prosperidad familiar, sino más bien obstáculos donde se incluyen, además de la discriminación de la mujer en la educación; la capacitación, la contratación, el acceso al crédito y el derecho a la propiedad y la herencia; los niveles de remuneración y frecuencia de promoción inferiores por igual trabajo; y las mayores responsabilidades domésticas. En el caso particular de las mujeres rurales y las trabajadoras migrantes, se ven particularmente afectadas durante los períodos de contracción económica en que son mucho más vulnerables al desempleo y suelen verse forzadas a soportar una carga aún mayor de trabajo no remunerado.

En nuestro país, en los últimos años, se han venido haciendo ingentes esfuerzos por lograr mayores niveles de equidad entre hombres y mujeres y esto es encomiable, visto desde la perspectiva de un interés consciente por sentar las bases de una política de género equilibrada y propositiva, cuyo fin último es una praxis de compartir roles en función del bien común, no obstante, es desde la educación a todos los niveles donde se debe de concebir una propuesta inclusiva de niños y niñas, de jóvenes en general y de adultos, donde ambos sexos tengan la oportunidad de formarse, pero en particular el sexo femenino, porque las presentes y las futuras madres que se instruyan, que tengan formación profesional es la garantía de hijos bien educados y eso lo hemos visto en la vida cotidiana, hay muchos ejemplos; por eso, es de imperiosa necesidad que las niñas no abandonen la escuela, que las jóvenes coronen su carrera técnica o profesional y que las actuales madres trabajadoras tengan acceso a formación técnica o en oficios y esto tiene un enorme significado para la familia, la comunidad y el país, juega un papel estratégico, porque estamos garantizando y promoviendo permanentemente la educabilidad, que en el amor maternal implica para los hijos, poder ser y deber ser, sobre todo en este siglo XXI centrado en el ser humano. 